\title{
Prevalence of airway obstruction in the elderly: results from a cross-sectional spirometric study of nine age cohorts between the ages of 60 and 93 years
}

\author{
Orsolya Szanto ${ }^{a}$, Peter Montnemery ${ }^{a}$, Solve Elmstahl ${ }^{a}$ \\ a Department of Health Sciences, Division of Geriatric Medicine, Lund University, Malmo, Sweden
}

Received 11th August 2009; revised 21st November 2009; accepted 7th January 2010; online 12th March 2010

\begin{abstract}
Aims: To study the prevalence of airway obstruction according to age, gender and smoking habits using spirometry, and to compare the results using different definitions, classifications and spirometric reference values in an elderly population.

Methods: A random sample of 2046 men and women in nine age cohorts (aged 60, 66, 72, 78, 81, 84, 87, 90 and 93 years) were drawn from the Swedish municipality registers. 1092 subjects performed spirometry of which 574 met ATS spirometric criteria.

Results: According to GOLD criteria (FEV $1 / F V C<0.7$ ) the prevalence of obstruction was $22.5 \%$ regardless of which one of three different spirometric reference values were used. Using the recently-changed Swedish National Guideline (SNG) recommendations - an FEV $1 /(\mathrm{F}) \mathrm{VC}$ ratio $<0.7$ in subjects younger than 65 years but an $\mathrm{FEV} / /(\mathrm{F}) \mathrm{VC}$ ratio $<0.65$ in subjects 65 years or older in order to define airway obstruction - the prevalence was $14.1 \%$ regardless of the applied spirometric reference values. Using the criterion $\mathrm{FEV} \mathrm{V}_{1} /(\mathrm{F}) \mathrm{VC}<\mathrm{expected}_{\mathrm{for}}$ age and gender (i.e. lower limit of normal, LLN) yielded the lowest prevalence of $10.1 \%$.

Conclusions: The prevalence of pulmonary obstruction depends on the criteria used for defining airway obstruction and on which spirometric normal values are applied. Using an age-adjusted FEV $1 /(F) V C$ LLN quotient to define pulmonary obstruction can be recommended on the basis of our results.

(C) 2010 Primary Care Respiratory Society UK. All rights reserved.

O Szanto et al. Prim Care Resp J 2010; 19(3): 231-236

doi:10.4104/pcrj.2010.00011
\end{abstract}

Keywords airway obstruction, criteria, prevalence, spirometry, spirometric reference values

\section{Introduction}

Depending on the criteria used and the population studied, the estimated prevalence rates of airway obstruction vary. In 2003 Halbert et al.' reported spirometry-based chronic obstructive pulmonary disease (COPD) prevalence rates ranging from $2 \%$ to $22.1 \%$ by searching MEDLINE literature back to the mid-1960s. In 2006 Halbert et al. ${ }^{2}$ reported that the pooled prevalence of COPD from 37 studies was $7.6 \%$. Viegi et al. ${ }^{3}$ reported prevalence rates for airway obstruction of $12.2 \%$ using European Respiratory Society (ERS) spirometry criteria, ${ }^{4}$ and $28.7 \%$ using American Thoracic Society (ATS) spirometry criteria, ${ }^{5}$ in an adult Italian population aged 46 to 73 years. Subsequently, Hardie et al. ${ }^{6}$ performed spirometry on 71 asymptomatic elderly never-smokers aged between 70 and
96 years in Bergen, Norway; approximately $35 \%$ of the subjects had a forced expiratory volume in one second $\left(\mathrm{FEV}_{1}\right)$ / forced vital capacity (FVC) ratio $<0.7$ which they defined as obstructive. In the age group $\geq 80$ years the corresponding prevalence rate was $50 \%$. Lundbäck et al. ${ }^{7}$ have reported a COPD prevalence rate of $11 \%$ among $46-47$ year old smokers, $42 \%$ among 61-62 years old smokers and 50\% among 76-77 years old smokers in Sweden using the Global Initiative for Chronic Obstructive Lung Disease $(\mathrm{GOLD})^{8}$ criteria and the Berglund et al. ${ }^{9}$ Swedish spirometric reference values.

Thus, the estimated prevalence rates of airway obstruction vary depending on the criteria used and the population studied. This is further emphasised by the lack of a generally accepted definition or classification of airway obstruction

\footnotetext{
* Corresponding author: Dr Peter Montnemery, Department of Health Sciences, Division of Geriatric Medicine , Lund University , SE-205 02 Malmo, Sweden. Tel: (+) 4640333471 Fax: (+) 4640336215 E-mail: peter.montnemery@home.se
} 
worldwide, although there are two internationally accepted criteria - GOLD 20088 and the 2004 ATS/ERS criteria. ${ }^{10}$

The aims of this study therefore were:

1. To compare the prevalence rates of airway obstruction using three different definitions to define airway obstruction: $\mathrm{FEV}_{1} /(\mathrm{F}) \mathrm{VC}$ ratio $<0.7 ; \mathrm{FEV}_{1} /(\mathrm{F}) \mathrm{VC}$ ratio $<0.7$ in subjects younger than 65 years but an $\mathrm{FEV}_{1} /(\mathrm{F}) \mathrm{VC}$ ratio $<0.65$ in subjects 65 years or older; and $\mathrm{FEV}_{1} /(\mathrm{F}) \mathrm{VC}$ less than $(<)$ expected for age and gender (i.e.; Lower Limit of Normal - LLN).

2. To investigate how the prevalence of airway obstruction varies when applying different spirometric reference values.

3. To determine the prevalence of airway obstruction by age, gender and smoking habits.

\section{Material and methods}

\section{Study population}

The study population was recruited from the population study "Good Ageing in Scania" performed in the southern part of Sweden which is part of an ongoing longitudinal Swedish investigation (The Swedish National study on Aging and Care, SNAC). ${ }^{11}$ In the present study a random sample of women and men in nine age cohorts (aged 60,66, 72, 78, 81, 84, 87, 90 and 93 years) were drawn from the municipality registers. Re-examinations are ongoing every third year, and new subjects aged 60 years old were included in order to study the age cohort effect. The shorter age intervals of three years for subjects 78 years and older is used because of attrition.

When presenting the results, those aged 60 and 66 years, those aged 72, 78 and 81 years, and those aged 84, 87, 90 and 93 years when sampled, were merged together into three age cohorts: 60-66 years; 72-81 years; and 84-93 years, respectively. The categorisation of the different age groups was done with the intention to describe age decade values explaining the different numbers of the age cohorts.

The total sample was 2046 subjects. During a period of 13 months from February 2001 to March 2002 this randomised population was invited by letter to a medical examination which included spirometry. Those responding to the invitation during this period and the following seven months were defined as participants.

The majority of the examinations were performed at the geriatric outpatient clinic at Malmö University Hospital, but 204 of 1092 subjects (19\%) were offered examination in their homes or in sheltered accommodation. An extensive questionnaire about lifestyle, smoking habits, current medication, health and life quality, was also performed. In-patient diagnoses were obtained from the Swedish Hospital Discharge Register of the National Board of Health and Welfare.

\section{Smoking habits}

Subjects were categorised as current-smokers, ex-smokers and never- smokers. Ex-smokers were defined as those who had quit smoking one or more years before they were investigated. Current-smokers were asked to state their consumption as $<5$ cigs/day, 5-14 cigs/day, or $>15$ cigs/day. Consumption of cigars, small cigars and pipe tobacco was converted to cigarettes: one cigar was considered to be equivalent to two cigarettes, 1.5 small cigars were considered to be equivalent to one cigarette, and 1 gram of tobacco was counted as one cigarette.

\section{Spirometry}

The spirometry recordings were performed using the Vitalograph 2120 electronic flow volume spirometer (Vitalograph Ltd., Maids Moreton House, Buckingham, MK18 1SW, England) connected to a laptop using the Spirotrac IV software (Vitalograph Ltd., Maids Moreton House, Buckingham, MK18 15W, England) following ATS guidelines. ${ }^{12}$ The same spirometer was used when the spirometry was performed at home.

\section{Statistical analysis}

The computer-based analysis programme SPSS (ver.13.0) was used in all calculations.

\section{Spirometric reference values}

Three different spirometric reference values were used in the analysis: the Swedish spirometric reference values published by Berglund et al. ${ }^{9}$ in 1963; the Swedish spirometric reference values by Hedenstrom et al..$^{13,14}$ published in 1985 and 1986; and the European spirometric reference values (ECSC). ${ }^{15}$ All three different spirometric reference values are in current use in Sweden.

\section{Guidelines and definitions}

Three guidelines were used for the definition and classification of airway obstruction: GOLD; ${ }^{8}$ the British Thoracic Society (BTS) guideline; ${ }^{16}$ and the Swedish National Guideline (SNG). ${ }^{17}$ GOLD defines COPD as $\mathrm{FEV}_{1} / \mathrm{FVC}<0.7$. However, in our analysis the highest of either the vital capacity (VC) or the FVC was used. The BTS guideline defines obstructive lung disease as $\mathrm{FEV}_{1} /(\mathrm{F}) \mathrm{VC}<0.7$, and the highest value of either VC or FVC should be used. Additionally the BTS criteria requires $\mathrm{FEV}_{1}$ to be $<80 \%$ of predicted for a diagnosis of COPD. The SNG ${ }^{17}$ has recently been changed and now recommends using an $\mathrm{FEV}_{1} /(\mathrm{F}) \mathrm{VC}$ ratio $<0.7$ in subjects younger than 65 years but an $\mathrm{FEV}_{1} /(\mathrm{F}) \mathrm{VC}$ ratio $<0.65$ in subjects 65 years or older in order to define COPD.

We also determined the prevalence rates of airway obstruction using the definition $\mathrm{FEV}_{1} /(\mathrm{F}) \mathrm{VC}<$ expected for age and gender (i.e.; LLN) using Hedenstrom et al. spirometric reference values. 13,14 $^{14}$ The equations are given as a footnote in Table 4.

\section{Results}

\section{Participation}

Of the total sample of 2046 individuals drawn from the municipality registers, 1092 participated in the study. Non- 
participants were made up of five groups: those who did not respond to the invitation letter (35); those who refused to participate (619); those who declined due to sickness (74) or due to difficulties in speaking Swedish (23); and those who died after the sampling period (203).

Of the 1092 participants, 574 performed an acceptable spirometry according to ATS criteria; these 574 subjects were defined as the study population (Table 1). The remaining 518 participants were defined as "excluded" (see Table 1). Of these 518,156 subjects were not able to perform spirometry; the other 362 did perform spirometry but of insufficient quality according to ATS criteria - most commonly, failure to achieve the reproducibility criteria. These spirometry results are presented in Table 2. In the excluded group, there were more subjects in the oldest age cohort, 84-93 years, but fewer subjects in the youngest age cohort 60-66 years. Smoking habits were similar except that there were more never-smokers in the study population. Pulmonary medication and hospital admissions were similar (see Table 1).

\section{Smoking habits}

Among men, $7.7 \%$ were current smokers, versus $16.1 \%$ among women. Almost half (49.1\%) of men were ex-smokers, versus $21.3 \%$ of women. $31.9 \%$ of men were never-smokers, versus $60.9 \%$ of women. Among the 96 current smokers, the majority consumed 5-14 cigarettes per day. In general, smoking decreased with increasing age. Details pertaining to smoking habits are shown in Table 3.

\section{Prevalence of airway obstruction in relation to different spirometric reference values and different guidelines}

The prevalence of airway obstruction according to the GOLD and the old SNG criteria $\left(\mathrm{FEV}_{1} /(\mathrm{F}) \mathrm{VC}<0.7\right)$ was $22.5 \%$ (129 subjects) regardless of which spirometric reference values were used. The prevalence of airway obstruction according to the BTS criteria ${ }^{16}$ varied depending on the spirometric values used: using Hedenström et al. ${ }^{13,14}$ it was $13.4 \%$ (77 subjects); using Berglund et al. ${ }^{9}$ it was $7.1 \%$ (41 subjects); and using ECSC 15 it was $10.6 \%$ (61 subjects). When applying the recently changed SNG guidelines ${ }^{17}$ - an $\mathrm{FEV}_{1} /(\mathrm{F}) \mathrm{VC}$ ratio $<0.7$ in subjects younger than 65 years but an $\mathrm{FEV}_{1} /(\mathrm{F}) \mathrm{VC}$ ratio $<0.65$ in subjects 65 years or older in order to define airway obstruction - the prevalence was $14.1 \%$ (81 subjects) regardless of the applied spirometric reference values. Using the criterion $\mathrm{FEV}_{1} /(\mathrm{F}) \mathrm{VC}<$ expected for age and gender (LLN) definition yielded a prevalence of $10.1 \%$ (58 subjects).

The classification of severity varied with the applied guidelines and the spirometric reference values used. Using the $\mathrm{GOLD}^{8}$ guidelines and the Berglund et al. ${ }^{9}$ spirometric reference values, $68.2 \%$ (88 subjects) were classified as mild, but using the old Swedish guidelines and the Berglund et al. spirometric reference values $20.9 \%$ (27 subjects) were classified as mild.
Table 1. Age, smoking habits, pulmonary medication and hospital admission in the study population $(n=574)$ and the excluded subjects $(n=518)$. Figures in percent

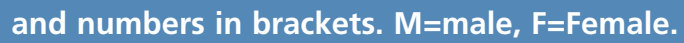

\begin{tabular}{|c|c|c|}
\hline & $\begin{array}{l}\text { Study population } \\
(n=574)\end{array}$ & $\begin{array}{l}\text { Excluded } \\
(n=518)\end{array}$ \\
\hline \multicolumn{3}{|l|}{ Age cohort } \\
\hline 60-71 & $34.8(n=200)$ & $26.1(n=135)$ \\
\hline $72-82$ & $36.9(n=212)$ & $36.5(n=189)$ \\
\hline $83-94$ & $28.2(n=162)$ & $37.5(n=194)$ \\
\hline Total & $100(n=574)$ & $100(n=518)$ \\
\hline \multicolumn{3}{|l|}{ Smoking habits } \\
\hline current-smokers & $16.7(n=96)$ & $14.1(n=73)$ \\
\hline ex-smokers & $32.2(n=185)$ & $32.0(n=166)$ \\
\hline never-smokers & $49.5(n=284)$ & $38.1(n=249)$ \\
\hline no smoking data & $1.6(n=9)$ & $3.8(n=30)$ \\
\hline total & $-100(n=574)$ & $100(n=518)$ \\
\hline \multicolumn{3}{|l|}{ Pulmonary medication } \\
\hline$\beta_{2}$ agonist & $4.4(n=25)$ & $7.0(n=36)$ \\
\hline steroids & $4.2(n=24)$ & $4.5(n=23)$ \\
\hline teofyllin & $1.2(n=7)$ & $2.1(n=11)$ \\
\hline acetylcystein & $3.3(n=19)$ & $3.5(n=18)$ \\
\hline combination $\beta_{2}$ \& steroids & $0.7(n=4)$ & $1.9(n=10)$ \\
\hline montelukast & $0.2(n=1)$ & $0(n=0)$ \\
\hline no pulmonary medication & $92.5(n=531)$ & $90.3(n=463)$ \\
\hline missing data & $0(n=0)$ & $1.0(n=5)$ \\
\hline total & $100(n=574)$ & $100(n=518)$ \\
\hline \multicolumn{3}{|l|}{ Hospital admission } \\
\hline cardiac failure & $1.7(n=10)$ & $1.0(n=5)$ \\
\hline cardiovascular disease & $2.6(n=15)$ & $3.5(n=18)$ \\
\hline chronic bronchitis & $0.3(n=2)$ & $0.4(n=2)$ \\
\hline COPD/asthma & $2.1(n=12)$ & $2.5(n=13)$ \\
\hline no hospital admission & $94.4(n=542)$ & $94.5(n=485)$ \\
\hline missing data & 0 & $1.0(n=5)$ \\
\hline total & $100(n=574)$ & $100(n=518)$ \\
\hline
\end{tabular}

Table 2 Prevalence of airway obstruction defined as $\mathrm{FEV}_{1} /(\mathrm{F}) \mathrm{VC}<0.7$ among those who fulfilled the acceptability criteria according to ATS and those who did not. Smoking data are given. Hedenstrom et al. normal spirometric values. Figures in percent.

\begin{tabular}{|c|c|c|}
\hline Age & $\begin{array}{l}\text { 60-94 } \\
\text { All who performed } \\
\text { an acceptable } \\
\text { spirometry }(n=565)\end{array}$ & $\begin{array}{c}60-94 \\
\text { No acceptable } \\
\text { spirometry } \\
(n=362)\end{array}$ \\
\hline $\begin{array}{l}\text { All } \\
\left.\text { FEV }_{1} /(\mathrm{F}) \vee \mathrm{C}\right)<0.7\end{array}$ & 22.5 & 21.0 \\
\hline $\begin{array}{l}\text { Current-smokers } \\
\left.\mathrm{FEV}_{1} /(\mathrm{F}) \mathrm{VC}\right)<0.7\end{array}$ & 41.7 & 39.3 \\
\hline $\begin{array}{l}\text { Ex-smokers } \\
\left.\mathrm{FEV}_{1} /(\mathrm{F}) \mathrm{VC}\right)<0.7\end{array}$ & 22.7 & 19.8 \\
\hline $\begin{array}{l}\text { Never-smokers } \\
\left.\mathrm{FEV}_{1} /(\mathrm{F}) \mathrm{VC}\right)<0.7\end{array}$ & 15.5 & 15.4 \\
\hline
\end{tabular}

$45 \%$ (58) of the subjects were classified as moderate using the GOLD criteria ${ }^{8}$ and the Hedenstrom et al. ${ }^{13,14}$ spirometric 
O Szanto et al.

Table 3. Smoking habits in the study population by age and gender ( $n=574)$. M=male, F=female. Figures in percent.

\begin{tabular}{|c|c|c|c|c|c|c|c|c|c|}
\hline \multirow{2}{*}{$\begin{array}{l}\text { Age cohorts } \\
\text { Gender }\end{array}$} & \multicolumn{3}{|c|}{$60-94$} & \multicolumn{2}{|c|}{$60-71$} & \multicolumn{2}{|c|}{$72-82$} & \multicolumn{2}{|c|}{$83-94$} \\
\hline & All $(n=574)$ & $M(n=226)$ & $F(n=348)$ & $M(n=90)$ & $F(n=110)$ & $M(n=86)$ & $F(n=126)$ & $M(n=50)$ & $F(n=112)$ \\
\hline \multicolumn{10}{|l|}{ Smoking habits } \\
\hline current-smokers & 16.7 & 17.7 & 16.1 & 26.7 & 27.3 & 15.1 & 10.3 & 6.0 & 11.6 \\
\hline ex-smokers & 32.2 & 49.1 & 21.3 & 45.6 & 30.0 & 54.7 & 25.4 & 46.0 & 8.0 \\
\hline never-smokers & 49.5 & 31.9 & 60.9 & 27.8 & 42.7 & 26.7 & 63.5 & 48.0 & 75.9 \\
\hline missing data & 1.6 & 1.3 & 1.7 & 0 & 0 & 3.5 & 0.8 & 0 & 4.5 \\
\hline \multicolumn{10}{|c|}{ Smoking consumption among smokers $(n=96)$} \\
\hline$<5$ cig/day & 12.5 & 7.5 & 16.1 & 4.1 & 13.3 & 15.4 & 7.7 & 0 & 30.8 \\
\hline 5-14 cig/day & 52.2 & 60.0 & 46.4 & 45.9 & 40.0 & 76.9 & 61.5 & 100 & 46.2 \\
\hline$>15$ cig/day & 32.3 & 32.5 & 32.1 & 50.0 & 40.0 & 7.7 & 30.8 & 0 & 15.4 \\
\hline missing data & 3.1 & 0 & 5.4 & 0 & 6.7 & 0 & 0 & 0 & 7.7 \\
\hline
\end{tabular}

Table 4 Prevalence of airway obstruction in the study population $(n=574)$ according to the GOLD, BTS, SNG criteria and FEV $_{1} /(\mathrm{F}) \mathrm{VC}<$ expected for age and gender (Lower Limit of Normal) using the Berglund et al., ESCS and Hedenstrom et al. normal spirometric values. Figures in percent and numbers in brackets. NA= not applicable.

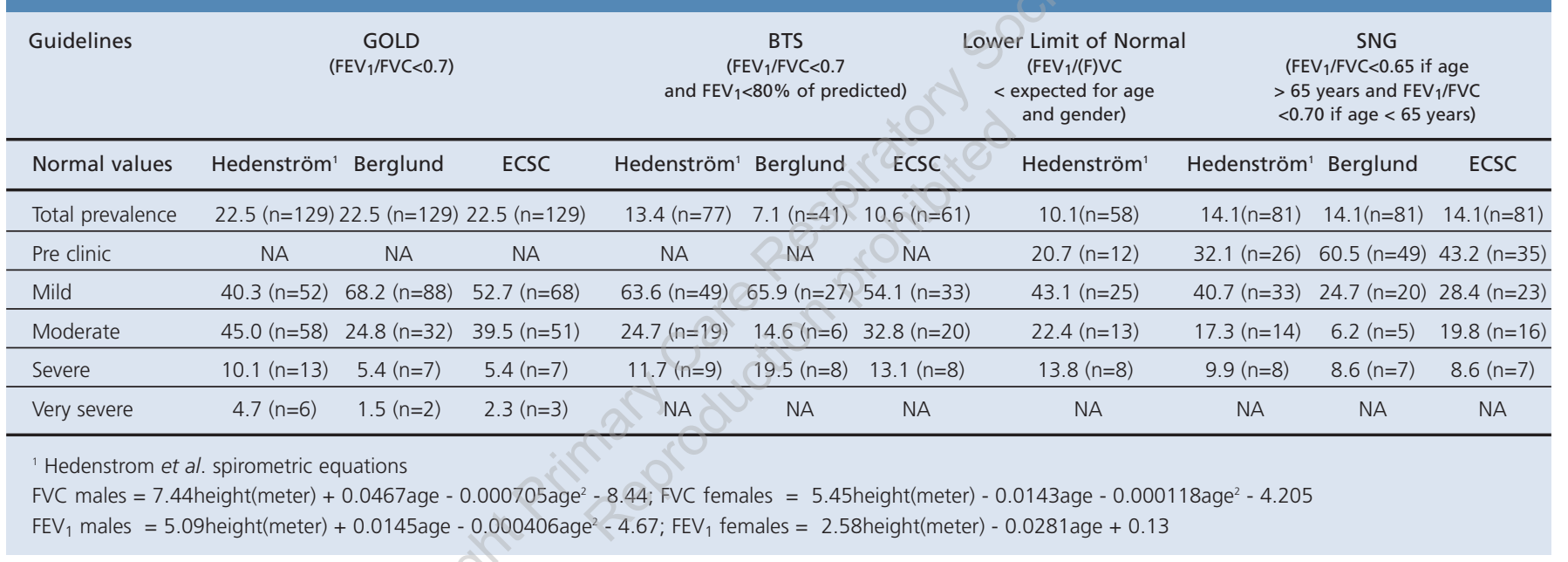

reference values, but only $4.7 \%$ (6) of the subjects were classified as moderate using the old Swedish guidelines and the Berglund et al. ${ }^{9}$ spirometric reference values. The corresponding figures for severe disease were $10.1 \%$ (13 subjects) and $6.2 \%$ (8 subjects), respectively (see Table 4).

\section{Prevalence of airway obstruction defined as}

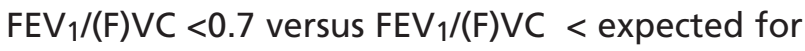
age and gender (Lower Limit of Normal)

The prevalence rates of airway obstruction were strongly related to smoking, and increased with increasing age except in the oldest age group 83-94 years.

In the whole population the prevalence of airway obstruction was $41.7 \%$ among smokers, $22.7 \%$ among exsmokers and $15.5 \%$ among never-smokers, using the criterion $\mathrm{FEV}_{1} /(\mathrm{F}) \mathrm{VC}<0.7$ to define obstruction. The corresponding figures using $\mathrm{FEV}_{1} /(\mathrm{F}) \mathrm{VC}$ <expected for age and gender (LLN) to define obstruction were $25.0 \%, 9.7 \%$ and $4.9 \%$ respectively. Therefore, using the $\mathrm{FEV}_{1} /(\mathrm{F}) \mathrm{VC}$ <expected for age and gender definition (LLN) yielded lower prevalence rates in all age groups and in both genders.

The highest prevalence, $76.9 \%$, was seen among current male smokers in the age cohort 72-81 years when airway obstruction was defined as $\mathrm{FEV}_{1} /(\mathrm{F}) \mathrm{VC}<0.7$. Using the criterion $\mathrm{FEV}_{1} /(\mathrm{F}) \mathrm{VC}<$ expected for age and gender (LLN) definition yielded a prevalence of $46.2 \%$ in the same group.

It is notable that $23.9 \%$ of never-smokers in the age cohort 84-93 years were classified as having obstructive lung disease using the criterion $\mathrm{FEV}_{1} /(\mathrm{F}) \mathrm{VC}<0.7$ to define obstruction, but only $10.1 \%$ were similarly defined as having obstructive disease using the age and gender adjusted ratio (LLN) - see Table 5 .

\section{Discussion}

The participation rate in our study was lower than previously reported in Norway in $2001^{18}$ and in three previous Swedish studies. 7,19,20 However, in the Swedish studies no subjects older than 69 years and 77 years were included, and in the 
Table 5. Variation in prevalence of airway obstruction defined $\mathrm{FEV}_{1} /(\mathrm{F}) \mathrm{VC}<0.7$ and Lower Limit of Normal

( $\mathrm{FEV}_{1} /(\mathrm{F}) \mathrm{VC}<$ expected for age and gender) in the study population $(\mathrm{n}=565)$ related to smoking habits. Hedenstrom et al. normal spirometric values . No smoking data in 9 subjects. M= males, $F=$ females. Figures in percent.

\begin{tabular}{|c|c|c|c|c|c|c|c|c|c|c|c|c|}
\hline \multirow{2}{*}{$\begin{array}{l}\text { Age cohorts } \\
\text { Gender }\end{array}$} & \multicolumn{4}{|c|}{$60-94$} & \multicolumn{3}{|c|}{$60-71$} & \multicolumn{2}{|c|}{$72-82$} & \multicolumn{3}{|c|}{$83-94$} \\
\hline & $\begin{array}{c}\text { All } \\
(n=565)\end{array}$ & $\underset{\substack{M \\
(n=223)}}{M}$ & $\begin{array}{c}F \\
(n=342)\end{array}$ & $\begin{array}{c}\text { All } \\
(n=200)\end{array}$ & $\begin{array}{c}M \\
(n=90)\end{array}$ & $\begin{array}{c}F \\
(n=110)\end{array}$ & $\begin{array}{c}\text { All } \\
(n=208)\end{array}$ & $\underset{(n=83)}{M}$ & $\begin{array}{c}F \\
(n=125)\end{array}$ & $\begin{array}{c}\text { All } \\
(n=157)\end{array}$ & $\underset{(n=50)}{M}$ & $\underset{(n=107)}{F}$ \\
\hline $\left.\mathrm{FEV}_{1} /(\mathrm{F}) \mathrm{VC}\right)<0.7$ & 41.7 & 50.0 & 35.7 & 35.2 & 33.3 & 36.7 & 57.7 & 76.9 & 38.5 & 37.5 & 66.7 & 30.8 \\
\hline \multicolumn{13}{|l|}{$\mathrm{FEV}_{1} /(\mathrm{F}) \mathrm{VC}<<$ Lower } \\
\hline Limit of Normal & 25.0 & 30.0 & 21.4 & 22.2 & 20.8 & 23.3 & 34.6 & 46.2 & 23.1 & 18.8 & 33.3 & 15.4 \\
\hline \multicolumn{13}{|l|}{$\mathrm{FEV}_{1} /(\mathrm{F}) \mathrm{VC}<$ Lower } \\
\hline Limit of Normal & 9.7 & 9.0 & 10.8 & 9.5 & 2.4 & 18.2 & 8.9 & 12.8 & 3.1 & 12.5 & 13.0 & 11.1 \\
\hline \multicolumn{13}{|l|}{ Never-smokers } \\
\hline $\left.\mathrm{FEV}_{1} /(\mathrm{F}) \mathrm{VC}\right)<0.7$ & 15.5 & 18.1 & 14.6 & 6.9 & 8.0 & 6.4 & 12.6 & 13.0 & 12.5 & 23.9 & 33.3 & 21.2 \\
\hline \multicolumn{13}{|l|}{$\mathrm{FEV}_{1} /(\mathrm{F}) \mathrm{VC}<$ Lower } \\
\hline Limit of Normal & 4.9 & 6.9 & 4.2 & 1.4 & 0 & 2.1 & 1.9 & 0 & 2.5 & 10.1 & 20.8 & 7.1 \\
\hline
\end{tabular}

Norwegian study no subjects older than 80 years were included. In our study about one third of the participants were older than 80 years and no restrictions or exclusions were made for sheltered living or suffering from dissembling conditions which is a strength of our study.

Furthermore, the recruitment procedure might have influenced the willingness to participate. Our subjects were sampled from the municipality registers. Those who participated in the Norwegian and Swedish studies were drawn from responders to a postal questionnaire, which might have positively influenced the willingness to participate.

Of the 1092 subjects who performed the spirometric tests, 574 subjects (53\%) were able to perform an acceptable spirometry according to ATS criteria. Failure to meet ATS criteria has previously been reported. ${ }^{18,21}$ We cannot fully exclude a selection bias where the healthiest and most mobile subjects might have been over-represented in the group who met the ATS criteria. However, those defined as the study population and those who were excluded did not differ very much in age, smoking habits, pulmonary medication or hospital admission, indicating that the study population was no healthier than the excluded group.

There is no fully accepted definition of COPD, but there are several international and national guidelines which use the spirometric quotient $\mathrm{FEV}_{1} / \mathrm{FV}(\mathrm{C})$ to define COPD. The BTS ${ }^{16}$ and $\mathrm{GOLD}^{8}$ have recommended a cut-off point for the $\mathrm{FEV}_{1} /(\mathrm{F}) \mathrm{VC}$ ratio of less than 0.7 . Additionally the BTS criteria requires the $\mathrm{FEV}_{1}$ to be $<80 \%$ of predicted spirometric reference values. The new SNG criteria $^{17}$ now recommend using an $\mathrm{FEV}_{1} /(\mathrm{F}) \mathrm{VC}$ ratio $<0.7$ in subjects younger than 65 years but an $\mathrm{FEV}_{1} /(\mathrm{F}) \mathrm{VC}$ ratio $<0.65$ in subjects 65 years or older. The GOLD and SNG criteria include a lung function test after a reversibility test, but the BTS criteria are not clear on that point. While no bronchodilatation tests were performed in our study we cannot fully exclude the possibility that some of those subjects with a reduced $\mathrm{FEV}_{1} / \mathrm{FV}(\mathrm{C})$ quotient had reversible obstruction to some degree which might have given an overestimation of the prevalence rate of airflow obstruction.

In addition, our study did not attempt to classify subjects as having COPD or asthma, but aimed instead to show how the prevalence of obstructive pulmonary disease varies by using different guidelines and spirometric reference values.

While the current definitions of obstructive pulmonary disease are founded on spirometry measurements, the applied spirometric reference values and the guidelines applied are crucial. ${ }^{20}$ Considering that the $\mathrm{FEV}_{1} /(\mathrm{F}) \mathrm{VC}$ ratio falls with age, ${ }^{13-15}$ the use of a fixed cut-off point for defining COPD overestimates the prevalence in the elderly and underestimates the prevalence in younger patients. The diagnosis and possible overestimation of COPD among the elderly has previously been reported. ${ }^{7,21-25}$ In the present study, as we expected, using a fixed $\mathrm{FEV}_{1} /(\mathrm{F}) \mathrm{VC}$ quotient resulted in the prevalence of lung obstruction increasing with increasing age. This finding was consistent among ex-smokers and never-smokers. It is notable that among current smokers there was a decrease in airway obstruction in the oldest age group aged 83-94 years. It can be speculated that the mortality rate due to obstructive pulmonary diseases among currentsmokers in this oldest age group has been higher compared to the younger age groups, thus explaining the lower prevalence figures. Using the $\mathrm{FEV}_{1} /(\mathrm{F}) \mathrm{VC}<$ expected for age and gender quotient resulted in a similar pattern except for lower prevalence figures in all age groups.

It is notable that $15.5 \%$ of never-smokers in the present study were classified as having obstruction using the $\mathrm{FEV}_{1} /(\mathrm{F}) \mathrm{VC}$ cut-off point of 0.7 compared to the figure of $4.9 \%$ when using the $\mathrm{FEV}_{1} /(\mathrm{F}) \mathrm{VC}$ <expected for age and 
gender (LLN) quotient. Lindberg et al. ${ }^{26}$ reported a COPD prevalence of $21 \%$ among $76-77$ years old non-smoking subjects using the GOLD criteria ${ }^{8}$ and Berglund et al. ${ }^{9}$ spirometric reference values, and $16 \%$ using the BTS ${ }^{16}$ criteria. These figures can be compared to our figure of $12.6 \%$ among never-smokers aged 72-82 years using the fixed $F E V_{1} /(F) V C$ cutoff point of 0.7 compared to $1.9 \%$ using the $\mathrm{FEV}_{1} /(\mathrm{F}) \mathrm{VC}$ <expected for age and gender (LLN) quotient.

\section{Conclusion}

The prevalence of pulmonary obstruction very much depends on the criteria used for defining airway obstruction and on the spirometric normal values which are applied. Defining and diagnosing pulmonary obstruction using a fixed $F E V_{1} /(F) \vee C$ quotient $<0.7$ is simple to use in clinical practice but might well result in underdiagnosis in younger subjects and overdiagnosis in older subjects. Using an age-adjusted $\mathrm{FEV}_{1} /(\mathrm{F}) \mathrm{VC}$ quotient using the LLN to define pulmonary obstruction can be recommended on the basis of our results.

\section{Acknowledgment}

The project Good Ageing in Skane is part of the Swedish National study on Ageing and Care (SNAC, www.snac.org) and is financially supported by the Swedish Ministry of Health and Social Affairs, Region Skåne, Länsförsäkringar and the Faculty of Medicine, Lund University. We are grateful to the participants, the participating county and municipalities.

\section{Conflict of interest declarations}

There are no conflicts of interest.

\section{References}

1. Halbert RJ, Isonaka S, George D, Iqbal A. Interpreting COPD Prevalence Estimates: What Is The True Burden of Disease? Chest 2003;123:1684-92. http://dx.doi.org/10.1378/chest.123.5.1684

2. Halbert RJ, Natoli JL, Gano A, Badamgarav E, Buist AS, Mannino DM. Global burden of COPD: systematic review and meta-analysis. Eur Respir J 2006; 28:523-32. http://dx.doi.org/10.1183/09031936.06.00124605

3. Viegi G, Pedreschi M, Pistelli F, Di Pede F, Baldacci S, Carrozzi L, Giuntini C. Prevalence of airways obstruction in a general population: European Respiratory Society vs American Thoracic Society definition. Chest 2000;117(5 Suppl 2):S339-45. http://dx.doi.org/10.1378/chest.117.5_suppl_2.339S

4. Siafakas NM, Vemeire P, Pride NB, et al. Optimal assessment and management of chronic obstructive pulmonary disease (COPD). Eur Respir J 1995;8:1398-20.

5. American Thoracic Society. Standards for the diagnosis and care of patients with chronic obstructive pulmonary disease. Am J Respir Crit Care Med 1995; 152:S77-120.

6. Hardie JA, Buist AS, Vollmer WM, Ellingsen I, Bakke PS, Morkve O. Risk of overdiagnosis of COPD in asymptomatic elderly never-smokers. Eur Respir J 2002; 20:1117-22. http://dx.doi.org/10.1183/09031936.02.00023202

7. Lundbäck $B$, Lindberg $A$, Lindström $M$ et al. Not 15 but $50 \%$ of smokers develop COPD?-Report from the Obstructive Lung Disease in Northern Sweden Studies. Respir Med 2003;97:115-22. http://dx.doi.org/ 10.1053/rmed.2003.1446

8. GOLD Global Strategy for the Diagnosis, Management, and Prevention of Chronic Obstructive Pulmonary Disease (Uppdated 2008): http://www.goldcopd.org

9. Berglund E, Birath G, Grimsby G, Kjellmer I, Sandqvist L, Söderholm B.
Spirometric studies in normal subjects. Forced expirograms in subjects between 7 and 70 years of age. Acta Med Scand 1963;173:185-92.

10. Celli B, MacNee W, and committee members. Standards for the diagnosis and treatment of patients with COPD: a summary of the ATS/ERS position paper. Eur Respir J 2004;23:932-46. http://dx.doi.org/10.1183/09031936.04.00014304

11. Lagergren $M$, Fratiglioni $L$, Hallberg IR et al. A longitudinal study integrating population, care and social services data. The Swedish National study on Aging and Care (SNAC). Aging Clin Exp Res 2004;16:158-68.

12. Standardization of Spirometry, 1994 Update. American Thoracic Society. Am J Respir Crit Care Med 1995;152:1107-36.

13. Hedenstrom $H$, Malmberg $P$, Agarwal K. Reference values for lung function tests in females. Regression equations with smoking variables. Bull Eur Physiopathol Respir 1985;21:551-7

14. Hedenstrom H, Malmberg P Fridriksson HV. Reference values for pulmonary function tests in men. Regression equations which include tobacco smoking variable. Uppsala J Med Sci 1986;91:299-10. http://dx.doi.org/10.3109/ 03009738609178670

15. Quanjer PH, Tammeling GJ, Cotes JE, Pedersen OF, Peslin R, Yernault JC. Lung volumes and forced ventilatory flows. Report Working Party Standardization of Lung Function Tests, European Community for Steel and Coal. Official Statement of the European Respiratory Society. Eur Respir J 1993;6(Suppl): S540.

16. British Thoracic Society. BTS Guidelines for the management of chronic obstructive pulmonary disease. Thorax 2004;59(Suppl):1-232.

17. The Swedish National Healthprogram for COPD. http://www.slmf.se/kol (in Swedish)

18. Langhammer A, Johnsen R, Gulsvik A, Holmen TL, Bjermer L. Forced spirometry reference values for Norwegian adults: the Bronchial Obstruction in NordTrondelag Study. Eur Resp J 2001;18:770-79.

19. Hasselgren M, Arne M, Lindahl A, Janson S, Lundback B. Estimated prevalences of respiratory symptoms, asthma and chronic obstructive pulmonary disease related to detection ratio in primary health care. Scand J Prim Health Care 2001; 19:54-7. http://dx.doi.org/10.1080/028134301300034701

20. Lindberg A, Jonsson AC, Romark E et al. Prevalence of Chronic Pulmonary Disease according to BTS, ERS, GOLD and ATS Criteria in Relation to Doctor's Diagnosis, Symptoms, Age, Gender. Respiration 2005;72:471-79. http://dx.doi.org/10.1159/000087670

21. Waterer GW, Wan JY, Kritchevsky SB, Wunderink RG, Satterfield S, Bauer DC, Newman AB, Taaffe DR, Jensen RL, Crapo RO; Health ABC Study. Airflow Limitation is Underrecognized in Well-Functioning Older People. J Am Geriatr Soc 2001;49:1032-8. http://dx.doi.org/10.1046/j.1532-5415.2001.49205.x

22. Medbö A, Melbye $H$. Lung function testing in the elderly-can we still use FEV1/FVC $<70 \%$ as a criterion of COPD? Respir Med 2007;101:1097-105.

23. Swanney MP, Ruppel G, Enright PL, Pedersen OF, Crapo RO, Miller MR, Jensen RL, Falaschetti E, Schouten JP, Hankinson JL, Stocks J, Quanjer PH. Using the lower limit of normal for the FEV1/FVC ratio reduces the misclassification of airways obstruction. Thorax 2008;63:1046-51. http://dx.doi.org/ 10.1136/thx.2008.098483

24. Hansen JE, Sun XG, Wasserman K. Spirometric criteria for airways obstruction: Use percentage of FEV1/FVC ratio below the fifth percentile, not $<70 \%$. Chest 2007;131:349-55. http://dx.doi.org/10.1378/chest.06-1349

25. Vollmer W, Gislason P, Burney P, Enright P, Gulsvik A, Kocabas A, Buist A. Comparison of spirometry criteria for the diagnosis of COPD: results from the BOLD study. Eur Respir J 2009;34:588-97. http://dx.doi.org/ 10.1183/09031936.00164608

26. Lindberg A, Bjerg-Backlund A, Ronmark E, Larsson LG, Lundback B. Prevalence and underdiagnosis of COPD by disease severity and the attributable fraction of smoking Report from the Obstructive Lung Disease in Northern Sweden Studies. Respir Med 2006;100:264-72. http://dx.doi.org/ 10.1016/j.rmed.2005.04.029 